\title{
Improved application technique of albumin-glutaraldehyde glue for repair of superficial lung defects
}

\author{
Maximilian Bures ${ }^{1}$, Patrick Zardo ${ }^{2}$, Florian Länger ${ }^{3}$ and Ruoyu Zhang ${ }^{4,5^{*}}$
}

\begin{abstract}
Background: Albumin-glutaraldehyde glue has gained widespread acceptance for treatment of alveolar air leaks (AAL) in thoracic surgery. As liquid run-off during application is detrimental to its sealing efficacy, we developed a modified technique and assessed it in vitro.
\end{abstract}

Methods: Caudal lobes of freshly excised swine lungs $(n=20)$ were intubated and ventilated. A standardized focal superficial parenchymal defect $(40 \times 25 \mathrm{~mm})$ was created on the inflated lung. AAL was assessed under exposure to increasing inspired tidal volume (TVi). Lung lobes were randomly selected and subjected to either a standard sealing suggested by the manufacturer (control group) or a modified technique relying on placement of a square silicone frame around the lesion site (study group). AAL was subsequently assessed until burst failure occurred and the occuring lesions length was recorded on the inflated lung to evaluate elasticity of underlying tissue.

Results: Superficial parenchymal defects resulted in AAL increasing with ascending TVi. AAL prior to sealant application was comparable in both groups. An application error occurred once in our control group. At TVi $=400$, 500, 600 and $700 \mathrm{ml}$, the albumin-glutaraldehyde glue achieved complete sealing in 10, 10, 9 and 8 lungs respectively in our study group, as opposed to 9, 7,6 and 4 lobes in the control group. The required mean burst pressure was significantly higher in our study group ( $41.0 \pm 1.0$ vs. $\left.37.5 \pm 4.2 \mathrm{cmH}_{2} \mathrm{O}, p=0.0195\right)$, but there was no difference in expansion of covered defect between both groups ( $1.0 \pm 0.4 \mathrm{vs} .1 .5 \pm 1.7 \mathrm{~mm}, p=0.3772)$.

Conclusions: Our tests suggest that frame-assisted sealant application might prevent glue run-off and thus improves its sealing efficacy. We encourage further investigation of this technique in well-designed, controlled clinical trials.

\section{Abstract in German}

Hintergrund: Albumin-Glutaraldehyd-Kleber ist zunehmend bei Behandlung des alveolo-pleuralen Luftlecks (AAL) in der Lungenchirurgie eingesetzt. Häufig kommt bei der Applikation unkontrolliertes Abfließen dieses flüssigen Klebers vor und führt zu Beeinträchtigung der Abdichtungswirksamkeit. Wir evaluierten in dieser Studie eine rahmengestützte Applikationstechnik mittels in vitro Lungenmodels.

(Continued on next page)

\footnotetext{
* Correspondence: zhang.ruoyu@yahoo.com;

zhang.ruoyu@klinik-schillerhoehe.de

${ }^{4}$ Department of Thoracic Surgery, Center for Pneumology and Thoracic

Surgery, Chest Hospital Schillerhoehe, Teaching hospital of the University of

Tuebingen, Gerlingen, Germany

${ }^{5}$ Department of Thoracic Surgery, Center for Pneumology and Thoracic

Surgery, Schillerhoehe Hospital, Solitudestr. 18, Gerlingen, Germany

Full list of author information is available at the end of the article
} 
(Continued from previous page)

Methode: Der kaudale Lappen der frisch entnommenen Schweinlungen $(n=20)$ wurde intubiert und beatmet. Eine pleurale Läsion $(40 \times 25 \mathrm{~mm})$ wurde erstellt und AAL mit steigendem inspiratorischem Tidalvolumen (TVi) untersucht. Die Lungenlappen wurden randomisiert mit Standardverfahren (Kontrollgruppe) oder mit der rahmengestützten Technik appliziert (Versuchsgruppe), wobei ein quadratischer Silikonrahmen um die Läsion platziert wurde. Nach Applikation von Albumin-Glutaraldehyd-Kleber wurde AAL auf die gleiche Weise gemessen bis zur Auftritt von Kleberbruch. Zur Untersuchung der Elastizität des Klebers wurde die Länge der pleuralen Läsion gemessen.

Ergebnis: Die oberflächliche pleurale Läsion führte bei aufsteigendem TVi zum Anstieg von AAL. Vor der Applikation des Klebers war AAL vergleichbar in den beiden Gruppen. Applikationsfehler trat bei einem Test in der Kontrolgruppe auf. Bei TVi $=400,500,600$ und $700 \mathrm{ml}$ führte der Albumin-Glutaraldehyd-Kleber zur kompletten Versieglung jeweils in 10, 10, 9 und 8 Lungen in der Versuchsgruppe, und 9, 7, 6 und 4 Lungen in der Kontrolgruppe. Der mittlere Bruchdruck war signifikant höher in Versuchsgruppe ( $41.0 \pm 1.0$ vs. $\left.37.5 \pm 4.2 \mathrm{cmH}_{2} \mathrm{O}, p=0.0195\right)$. Allerdings bestand kein Unterschied an Dehnung der versiegelten pleuralen Läsion in den beiden Gruppen (1.0 \pm 0.4 vs. $1.5 \pm 1.7 \mathrm{~mm}, p=0.3772)$.

Schlussfolgerung: Unsere in vitro Versuche zeigten, dass die rahmengestützte Applikationstechnik unkontrolliertes Abfließen des flüssigen Klebers effektiv verhindern und die Abdichtungswirksamkeit vom Albumin-Glutaraldehyd-Kleber verbessern kann. Wir empfehlen weitere Untersuchungen dieser Applikationstechnik in gut gestalteten, kontrollierten klinischen Studien.

Keywords: Lung, Air leaks, Sealant, BioGlue, Application

\section{Background}

Superficial parenchymal lung defects are common sequelae of lung surgery, particularly in patients with firm pleural adhesions or incomplete fissures. They result in alveolar air leaks (AAL), which are associated with prolonged chest tube duration and hospital stay as well as higher postoperative morbidity [1-3]. In the past decade surgical sealants have been increasingly used in treating AAL as adjuncts to conventional surgical closing techniques [4]. One of the most commonly used sealants is BioGlue $^{\mathrm{Tm}}$ (CryoLife Europa Ltd., Surrey, UK), which is composed of bovine serum albumin and glutaraldehyde [5]. Its clinical benefits for treating AAL have been proven in various clinical trials [6-8]. In addition, our previous in vitro experiment has confirmed the high sealing efficacy of BioGlue ${ }^{\mathrm{Ts}}$, which is superior in resisting higher ventilation pressure [9].

BioGlue $^{\mathrm{rm}}$ is delivered in liquid form, which makes it prone to unintentional run-off. Reported consequences include among others a blocked leaflet after mechanical aortic valve replacement resulting in a high transvalvular gradient [10]. Our personal experience in lung surgery confirms that BioGlue ${ }^{\mathrm{ma}}$ run-off after sealing superficial lung defects is almost inevitable and leads to hardened strands often far away from the original lesion site. These unintentional run-offs decrease the amount of sealant on the lesion which might reduce its sealing efficacy. Moreover, due to the rigid nature of hardened Bio$\mathrm{Glue}^{\mathrm{tm}}$, overflowing sealant might impair expansion of adjacent lung parenchyma.

In the present study we used an established in vitro lung model to examine whether a special application technique based on a silicone frame that is placed around lung defects might improve the sealing efficacy of BioGlue [11].

\section{Methods \\ Experimental protocol}

Lungs of German landrace pigs were freshly excised in a local slaughterhouse. Within two hours following harvest, the lungs were dissected along the trachea until the tracheal bifurcation was reached. The caudal lobe was selectively intubated, ventilated and immersed in water to ensure impermeability. After connection to the ventilation machine (Evita, Dräger, Lübeck, Germany), the caudal lobe was ventilated in volume-controlled mode with a PEEP of $5 \mathrm{cmH}_{2} \mathrm{O}$, an I:E ratio of 1:2 and a frequency of $12 / \mathrm{min}$. The caudal lobe was fully inflated when inspiratory tidal volume $(\mathrm{TVi}) \geq 400 \mathrm{~mL}$. Overinflation of the lobe was observed with $\mathrm{TVi} \geq 800 \mathrm{~mL}$. A superficial parenchymal lesion was created in a previously marked area of $40 \times 25 \mathrm{~mm}$ on the inflated caudal lobe with gentle pressure from a small drill with a roughened conic head, working from the margins towards the lesions center. Marker spots were then applied to the cranial and caudal edge of the lesion. Starting ventilation at $\mathrm{TVi}=300 \mathrm{ml}$, TVi was increased by $100 \mathrm{ml}$ in steps until a maximal inspiratory pressure (Pmax) of $40 \mathrm{cmH}_{2} \mathrm{O}$ was reached. Following each increase in $\mathrm{TVi}$, the expiratory tidal volume (TVe), resistance, compliance, as well as Pmax, mean inspiratory pressure (Pmean) and plateau inspiratory pressure (Pplat) were recorded after five cycles. AAL was calculated as the difference between TVi and TVe.

Lung lobes were randomly selected and subjected to either a standard technique sealing in accordance with 
CryoLife guidelines (control group, $n=10$ ) or a modified technique relying on placement of a square silicone frame around the lesion site (study group, $n=10$ ). Standard sealant application consists in carefully meandering along the lesion surface and, in accordance with user guidelines, respecting a safety margin of $1 \mathrm{~cm}$ to all sides. For our modified technique, a silicone frame (transparent silicone $60 \pm 5$ Shore, Erik's NordOst GmbH, Hannover, Germany) customized to allow for the mentioned safety margin, was placed around the lesion on the inflated lower lobe (Fig. 1). Afterwards glue was applied within frame borders in the same meandering fashion. In both groups a period of $60 \mathrm{~s}$ was awaited until the glue hardened and full sealant adhesion was achieved (Fig. 2). In this experiment the sealant was applied exclusively in $2 \mathrm{ml}$ syringes, using only one sample for each lesion.

The caudal lobe was then ventilated again with $\mathrm{TVi}$ rising slowly from $100 \mathrm{ml}$. Commencing at $\mathrm{TVi}=400 \mathrm{ml}$ the same parameters as prior were recorded, continuously screening for bubbles under water application. The distance between marker spots was measured with each increase for the evaluation of elasticity. Air leak was assessed through air bubble observation by two independent investigators. Any disagreement would be arbitrated by a third investigator. Sealing was considered successful, when no bubble was visible under submersion after five cycles of ventilation. This corresponds to grade 0 on the Macchiarini scale [11]. Sealing failure was determined once air bubbles were observed (grade 1 or higher). In the moment of sealant failure Pmax was recorded as burst pressure. Sealant failure was furthermore categorized into adhesive or cohesive failure. Adhesive failure was considered if the sealant failure occurred at the interface between sealant and parenchymal defect. Cohesive failure was defined as failure within the sealant. When cohesive or adhesive failure was observed before

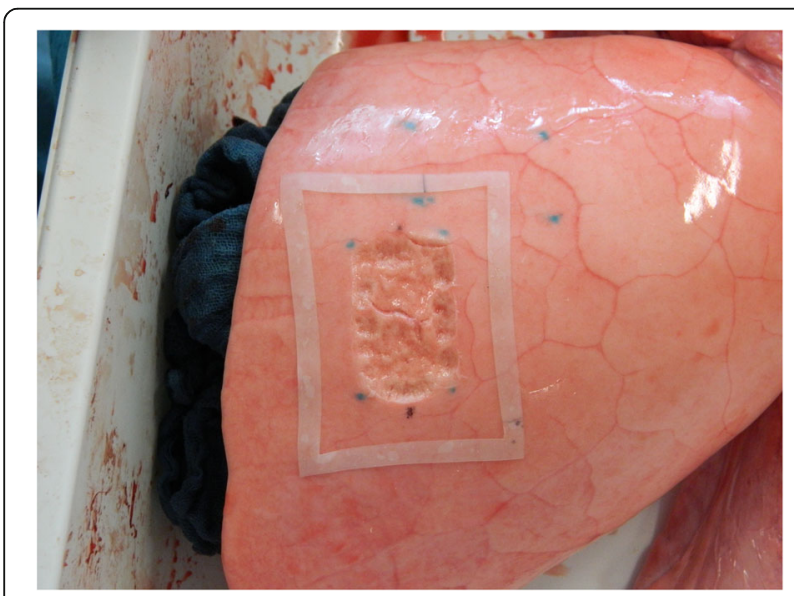

Fig. 1 Placement of a silicone frame around a parenchymal lesion $(40 \times 25 \mathrm{~mm})$

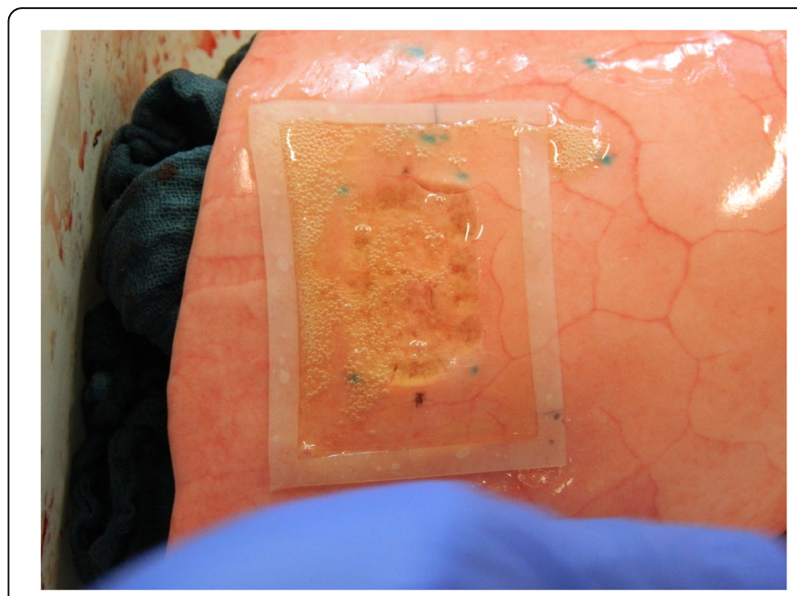

Fig. 2 Applied BioGlue ${ }^{\mathrm{TM}}$ within the borders of the silicone frame

starting the test at $\mathrm{TVi}=400 \mathrm{ml}$, this was considered application error.

\section{Statistical analysis}

The normality of variables was tested using the Kolmogorov-Smirnov one-sample-test. Descriptive statistics are presented as mean \pm standard deviation in case of normal distribution. Multiple linear regression was used to determine the ventilation parameters' correlation with AAL. Statistical significance was assumed if $p<0.05$. All statistical analysis was performed using SPSS (version 16.0 for Windows; SPSS Inc., Chicago, Illinois, USA).

\section{Results}

Following a set of four pilot tests for our modified technique, a total of 20 consecutive tests were undertaken by means of the standard and frame application techniques in a randomized manner (see the Additional file 1).

AAL prior to glue application were comparable in both groups (Table 1). Application error occured once during standard application. At TVi $=400,500,600,700$ and $800 \mathrm{ml}$, BioGlue ${ }^{\mathrm{ma}}$ achieved sealing in 10, 10, 9, 8 and 8 lobes in the study group, while 9, 7, 6, 4 and 2 lobes were sealed in the control group, respectively. Even in over-inflated lobes $(\mathrm{TVi}=900 \mathrm{ml})$, superficial defects were still sealed in four tests in our study group, while only one lobe remained sealed in the control group. Sealing rates of both groups are presented in Fig. 3 .

Table 1 Air leak assessment before sealant application

\begin{tabular}{lccc}
\hline TVi $(\mathrm{ml})$ & Study group $(n=10)$ & Control group $(n=10)$ & $p$ value \\
\hline 400 & $73.0 \pm 41.0$ & $75.0 \pm 36.9$ & 0.9146 \\
500 & $110.0 \pm 47.7$ & $116.0 \pm 56.8$ & 0.8110 \\
600 & $167.0 \pm 64.5$ & $168.0 \pm 71.0$ & 0.9754 \\
700 & $226.0 \pm 69.0$ & $225.0 \pm 89.2$ & 0.9791
\end{tabular}

$T V i$ inspired tidal volume 


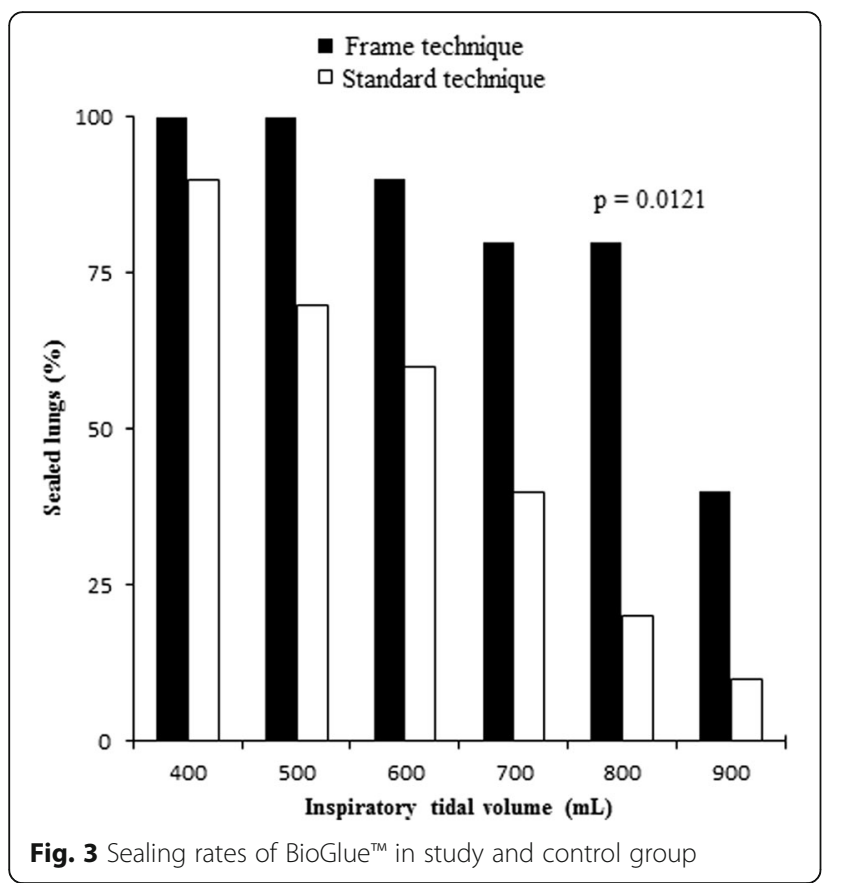

Difference in sealing rate between both groups reached statistical significance at $\mathrm{TVi}=800 \mathrm{ml}(80 \%$ vs. $20 \%$, $p=0.0121$ ).

Mean burst pressure was significantly higher in the study group than in the control group $\left(41.0 \pm 1.0 \mathrm{cmH}_{2} \mathrm{O}\right.$ versus $\left.37.5 \pm 4.2 \mathrm{cmH}_{2} \mathrm{O}, p=0.0195\right)$. Both groups exhibited only cohesive sealant failures. Concerning elasticity, there was no difference in expansion of the covered defect between both application techniques (1.0 \pm 0.4 vs. $1.5 \pm 1.7 \mathrm{~mm}, p=0.3772)$.

\section{Discussion}

As a highly effective sealant, BioGlue ${ }^{\mathrm{Tm}}$ is regularly implemented in cardiovascular surgery for hemostasis [5]. In lung surgery it has gained widespread acceptance as an adjunct in treating AAL in recent years [7]. A major drawback of its application in liquid form on the surface of inflated lung tissue is sealant run-off, which in turn may impair sealing efficacy and trap surrounding parenchyma. Recently our group has developed a special application technique which basically consists in placing a silicone frame around the lesion site to prevent sealant run-off (frame technique). The present in vitro experiment was aimed to examine whether this special applicaiton technique might improve the sealing efficacy of BioGlue ${ }^{\mathrm{TM}}$.

To assess sealing efficacy we used an established in vitro lung model in the present study, which has been proven reliable in the previous experiments $[9,12]$. In a randomized order BioGlue ${ }^{\mathrm{Tm}}$ was applied onto standardized superfical lung defects by means of the standard technique according to the usage guide or the frame technique. The testing results of the standard application technique demonstrated a high sealing efficacy of BioGlue $^{\mathrm{Tx}}$ in treating AAL. The mean burst pressure was very close to the upper limit of the commonly applied ventilation pressure $\left(40 \mathrm{cmH}_{2} \mathrm{O}\right)$. However, when a silicone frame was placed around lesion site, run-off of the liquid sealant could be prevented and the sealing efficacy presented as sealing rate and burst pressure was significantly improved. In majour lung resection, division of incomplete fissures is often inevitable and causes superficial parenchymal lung defects and postoperative prolonged air leaks despite meticulous surgical technique. In many cases, the defect is not horizontal, rendering adaequate applicaion of BioGlue ${ }^{\mathrm{Tm}}$ difficult. According to our results, it is reasonable to speculate that the frameassisted application technique might facilitate sealing air leaks in this specific setting. Nevertheless, the potential clinical benefits and practical implications of this special application technique require confirmation from welldesigned randomized clinical trials.

In the present in vitro experiment we used a square silicone frame to test the special application technique. The measurement of the lesion's length before and after sealant application indicated that the silicone frame did not alter the elasticity of the underlying lung tissue. Despite the wide use of silicone in surgical practice, caution should be taken for potential side effects of this non-absorbable material. While concern has been arised about the chronic foreign body reactions and potential risk for carcinogenesis associated with silicone implants [13, 14], there have been report that implanted silicone may even be a protective factor concerning the development of carcinoma [15]. Taken together, the potential side effects of the present application technique deserves further investigation.

As video-assisted thoracic surgery (VATS) has been widely adopted and practiced in lung surgery in the last two decades, air leak sealing by means of topical sealant application through trocars has becomen a feasible approach [16]. A ample body of evidence demonstrates that prolonged air leaks are still one of the major complications after VATS major lung resections and limit the clinical benefits of this minimally invasive approach [17]. As liquid sealant BioGlue ${ }^{\text {Tw }}$ can also be applied thoracoscopically using a delivery tip extention. In this aspect, the present study might stimulate further investigation and improve the air leak management during VATS procedures.

One of the limitations of the present experiment is the certain inevitable variation in the size of tested procine lobes. To minimize this confounding feature, the lungs were harvested from the pigs in almost the same weight. As all lobes were fully inflated with a TVi of $400 \mathrm{ml}$, no significant differences were noted in this regard. In addition, the randomization of the application techniques might also contribute in reducing this bias. The authors recognize that the sealant applications were not 
blinded for the assessment of air tightness and the measurement of the lesion's length in the present experiment. I t may have resulted in information bias, which was certainly minimized by randomization of the application techniques. Finally, the observation bias might have arisen due to the inevitable subjectiveness in the judgment of air bubbles, even though it was performed by two investigators independently. Nevertheless, the statistic analysis revealed significant results in favor to the application technique with silicone frame. We believe that our investigation is a further step to improve the application of fluid glue and useful to prevent prolonged postoperative air leaks after lung resection. Future efforts will need to be directed both towards assessing the effectiveness of the frame-assisted application technique in well designed clinical trails and towards examination of absorbable materials as frame.

\section{Conclusion}

Our in vitro tests indicated that application by means of the frame technique prevents glue run-off and improve the sealing efficacy of BioGlue ${ }^{\mathrm{tr}}$. The implications of this special application technique should be further analyzed in well-designed, controlled clinical trials.

\section{Additional file}

Additional file 1: Results of individual tests. (XLS 63 kb)

\section{Abbreviations}

AAL: Alveolar air leak; PEEP: Positive end-expiratory pressure; Pmax: Maximal inspiratory pressure; Pmean: Mean inspiratory pressure: Pplat: Plateau inspiratory pressure; TVe: Expiratory tidal volume; TVi: Inspired tidal volume

\section{Acknowledgements}

The BioGlue ${ }^{T M}$ samples used for this study were provided by CryoLife Europa, Ltd.. Special thanks to Mr. Stefan Pingel for his support in this regard. We also acknowledge support by Deutsche Forschungsgemeinschaft and Open Access Publishing Fund of University of Tübingen.

\section{Funding}

This experimental work was not funded.

\section{Availability of data and materials}

Please contact authors for data requests.

\section{Authors' contributions}

MB carried out the conception and design of the study, in vitro tests, acquisition of data, analysis and interpretation of the data, statistical analysis as well as drafting of the manuscript. PZ participated in acquisition, analysis and interpretation of the data, critical revision of the manuscript and supervision of the study. FL participated in histological examination. RZ participated in the conception and design of the study, acquisition and interpretation of the data, drafting and critical revision of the manuscript. All authors read and approved the final manuscript.

\section{Competing interests}

The authors declare that they have no competing interests.

\section{Ethics approval}

The lungs used in the tests were freshly excised from pigs, which were euthanized in a local slaughterhouse.

These pigs were not bred for the purpose of animal experiments. According to the statement of the local Committee for Animal Care an ethical approval was not required for the present in vitro experiment.

\section{Author details}

${ }^{1}$ Department of Cardiac, Thoracic, Transplantation and Vascular Surgery, Hannover Medical School, Hannover, Germany. ${ }^{2}$ Department of Cardiac and Thoracic Surgery, Otto-von-Guericke University Magdeburg, Magdeburg, Germany. ${ }^{3}$ Department of Pathology, Hannover Medical School, Carl-Neuberg Str. 1, 30625 Hannover, Germany. ${ }^{4}$ Department of Thoracic Surgery, Center for Pneumology and Thoracic Surgery, Chest Hospital Schillerhoehe, Teaching hospital of the University of Tuebingen, Gerlingen, Germany. ${ }^{5}$ Department of Thoracic Surgery, Center for Pneumology and Thoracic Surgery, Schillerhoehe Hospital, Solitudestr. 18, Gerlingen, Germany.

Received: 17 June 2016 Accepted: 14 October 2016

Published online: 21 October 2016

\section{References}

1. Abolhoda A, Liu D, Brooks A, Burt M. Prolonged air leak following radical upper lobectomy: an analysis of incidence and possible risk factors. Chest. 1998;113:1507-10

2. Bardell T, Petsikas D. What keeps postpulmonary resection patients in hospital? Can Respir J. 2003;10:86-9.

3. Okereke I, Murthy SC, Alster JM, Blackstone EH, Rice TW. Characterization and importance of air leak after lobectomy. Ann Thorac Surg. 2005;79:1 167-73.

4. Belda-Sanchis J, Serra-Mitjans M, Iglesias Sentis M, Rami R. Surgical sealant for preventing air leaks after pulmonary resections in patients with lung cancer. Cochrane Database Syst Rev. 2010:Cd003051.

5. Chao HH, Torchiana DF. BioGlue: albumin/glutaraldehyde sealant in cardiac surgery. J Card Surg. 2003;18:500-3.

6. Tansley P, Al-Mulhim F, Lim E, Ladas G, Goldstraw P. A prospective, randomized, controlled trial of the effectiveness of BioGlue in treating alveolar air leaks. J Thorac Cardiovasc Surg. 2006;132:105-12.

7. Passage J, Tam R, Windsor M, O'Brien M. Bioglue: a review of the use of this new surgical adhesive in thoracic surgery. ANZ J Surg. 2005;75:315-8.

8. Pedersen TB, Honge JL, Pilegaard HK, Hasenkam JM. Comparative study of lung sealants in a porcine ex vivo model. Ann Thorac Surg. 2012;94:234-40.

9. Zhang R, Bures M, Hoffler K, Jonigk D, Haverich A, Krueger M. In vitro comparison of two widely used surgical sealants for treating alveolar air leak. Thorac Cardiovasc Surg. 2014:62:705-9.

10. Gabrijelcic T. Blockage of a mechanical aortic valve leaflet with Bioglue: a case report. Heart Surg Forum. 2012;15:E310-312.

11. Macchiarini P, Wain J, Almy S, Dartevelle P. Experimental and clinical evaluation of a new synthetic, absorbable sealant to reduce air leaks in thoracic operations. J Thorac Cardiovasc Surg. 1999;117:751-8.

12. Zhang R, Bures M, Hoffler HK, Zinne N, Langer F, Bisdas T, et al. TissuePatch as a novel synthetic sealant for repair of superficial lung defect: in vitro tests results. Ann Surg Innov Res. 2012;6:12.

13. James SJ, Pogribna M, Miller BJ, Bolon B, Muskhelishvili L. Characterization of cellular response to silicone implants in rats: implications for foreign-body carcinogenesis. Biomaterials. 1997;18:667-75.

14. Perricone C, Colafrancesco S, Mazor RD, Soriano A, Agmon-Levin N, Shoenfeld Y. Autoimmune/inflammatory syndrome induced by adjuvants (ASIA) 2013: Unveiling the pathogenic, clinical and diagnostic aspects. J Autoimmun. 2013:47:1-16.

15. Su CW, Dreyfuss DA, Krizek TJ, Leoni KJ. Silicone implants and the inhibition of cancer. Plast Reconstr Surg. 1995;96:513-8. discussion 519-520.

16. Carrillo EH, Kozloff M, Saridakis A, Bragg S, Levy J. Thoracoscopic application of a topical sealant for the management of persistent posttraumatic pneumothorax. J Trauma. 2006;60:111-4.

17. Shaw JP, Dembitzer FR, Wisnivesky JP, Litle VR, Weiser TS, Yun J, et al. Video-assisted thoracoscopic lobectomy: state of the art and future directions. Ann Thorac Surg. 2008;85:S705-709. 